\title{
FUNGSI KIDUNG JULA JULI LUDRUK JAWA TIMUR
}

\author{
Eko Cahyo Prawoto \\ Pana Pramulia \\ Universitas PGRI Adi Buana Surabaya \\ e-mail: ecahyop@gmail.com, panapramulia@unipasby.ac.id
}

\begin{abstract}
Abstrak: Kidung Jula Juli merupakan sastra lisan yang sudah ada sejak dulu kala, dan diwariskan secara turun-temurun. Kidung Jula Juli lahir dan berkembang di Jawa Timur, kidung Jula Juli dalam wujudnya berbentuk pantun jenaka yang berisi, sindiran, kritikan, hingga nasihat, tentang kehidupan masyarakat,pendidikan, politik, dsb. Kidungan Jula Juli dalam fungsinya merupakan pranata sosial yang mengarahkan serta mengingatkan masyarakat untuk menyikapi permasalahan-permasalahan kehidupan dengan bijak, sesuai dengan norma-norma yang berlaku. Oleh sebab itu, penelitian pada Kidung Jula Juli Jawa Timur dilakukan untuk mengetahui serta mendeskripsikan fungsi kidung tersebut sebagai sebuah sastra lisan. Peneliti menggunakan pendekatan kualitatif deskriptif. Adapun sumber data yang digunakan dalam penelitian ini ialah enam video pertunjukan ludruk, dengan judul sebagai berikut, Soto Gagak, Kidung Lawakan, Kemanten Kisinan, Tumpeng Maut, Kejeglek Anak Dewe, Balai Kota. Semua data tersebut diperoleh dari youtube. Semua Kidung Jula Juli yang digunakan sebagai sumber data tersebut dibawakan oleh Cak Kartolo (CK). Sedangkan data dalam penelitian ini ialah tuturan yang dialihwanahakan dalam bentuk bait dan larik yang mengandung fungsi-fungsi tersebut di atas. Dalam memperoleh data, peneliti menggunakan teknik pengumpulan data melalui beberapa tahapan sebagaimana berikut. 1) mencari video pertunjukan ludruk/kidung jula-juli yang dibawakan oleh Kartolo di youtube, 2) mengunduh video pertunjukan ludruk yang sudah diidentifikasi sebelumnya, 3) menyimpan video pertunjukan ludruk tersebut dalam satu folder, 4) memberi identitas pada setiap video (contoh; Kidung 1, 2, dst.). Teknik analisis data dengan beberapa tahapan sebagai berikut; 1) transkripsi Kidung Jula Juli pada enam video tersebut, 2) pengodean pada setiap data yang sesuai dengan tujuan penelitian, untuk memudahkan penelitia dalam melakukan identitikasi, 3) klasifikasi data berdasarkan empat fungsi Kidung Jula Juli, 4) interpretasi data berdasarkan empat fungsi tersebut pada setiap bait Kidung Jula Juli, 5) yang terakhir ialah pengambilan kesimpulan yang berdasar pada keseluruhan analisis data. Hasil penelitian ini ialah sesuai dengan tujuan penelitian bahwa diperoleh: 1) Kidung Jula Juli merupakan hiburan dalam fragmen ludruk Jawa Timur, 2) sebagai pranata dalam kehidupan masyarakat, sebagai media pembelajaran bagi anak-anak, d) sebagai pengejawantahan norma-norma yang berlaku di masyarakat.
\end{abstract}

Kata Kunci: fungsi, kidung, ludruk 


\title{
FUNCTION OF KIDUNG JULA JULI LUDRUK EAST JAVA
}

\author{
Eko Cahyo Prawoto \\ Pana Pramulia \\ PGRI Adi Buana University Surabaya \\ e-mail: ecahyop@gmail.com, panapramulia@unipasby.ac.id
}

\begin{abstract}
The Song of Jula Juli is an oral literature that has existed since time immemorial, and has been passed down from generation to generation. The Song of Jula Juli was born and developed in East Java, the Song of Jula Juli in its form in the form of humorous poetry that contains, satire, criticism, to advice, about community life, education, politics, etc. The function of Jula Juli in its function is a social institution that directs and reminds the public to address life's problems wisely, in accordance with applicable norms. Therefore, research on the Song of Jula Juli East Java was conducted to find out and describe the function of the song as an oral literature. Researchers used a descriptive qualitative approach. The data sources used in this study are six video performances of ludruk, with the following titles, Soto Gagak, Kidung Lawakan, Kemanten Kisinan, Death Tumpeng, Kejeglek Anak Dewe, City Hall. All data is obtained from YouTube. All of the July Song Songs used as the data source were presented by Cak Kartolo (CK). While the data in this study are utterances which are transcribed in the form of stanzas and arrays containing the functions mentioned above. In obtaining data, researchers used data collection techniques through several stages as follows. 1) looking for videos of the ludruk / jula-juli performances performed by Kartolo on youtube, 2) downloading the ludruk show videos that have been identified previously, 3) storing the ludruk show videos in one folder, 4) giving an identity to each video (for example; Song 1, 2, etc.). Data analysis techniques with the following stages; 1) the transcription of the Song of July Jula on the six videos, 2) the coding of each data in accordance with the purpose of the study, to facilitate research in identifying, 3) the classification of data based on the four functions of the Song of Jula July, 4) interpretation of data based on the four functions mentioned in the each verse of the Song of Song Jula July, 5) the last is the conclusion based on the overall analysis of the data. The results of this study are in accordance with the research objectives that are obtained: 1) Song of July Jula is entertainment in East Java ludruk fragments, 2) as a institution in community life, as a learning medium for children, d) as a manifestation of the norms that apply in Public.
\end{abstract}

Keywords: function, song, ludruk 


\section{A. PENDAHULUAN}

Bandem dan Sal Murgiyanto (1996:136) ludruk adalah sebuah teater rakyat yang sangat populer di daerah surabaya dan sekitar Jawa Timur. Semua pemainya pria, termasuk untuk peran-peran wanita. Rupanya, di sinilah letak daya tarik ludruk sebagai tontonan khas. Berbeda dengan Wayang Topeng dan Wayang Wang, Ludruk membawakan cerita dengan gerak laku yang realistis dan lebih mementingkan dialog serta banyolan. Ludruk tidak pernah mendapat sentuhan seniman istana; sebaliknya, hidup dan berkembang di kalangan rakyat jelata sebagai tontonan hiburan.

Prasisko (2018) ludruk adalah seni pertunjukkan yang tumbuh dan berkembang di Jawa Timur, dalam wujudnya seni pertunjukan tersebut memuat persinggungan antara tradisional dengan modern, melalui kidung/parikan, lakon, dialog, dan tarian. Penggunaan bahasa dalam pertunjukkan ludruk sangat identik dengan bahasa Suroboyoan (Bahasa Jawa arek) yang mengungkap ekspresi kasar atau Jawa ngoko. Dalam pertunjukkanya ludruk mengajak para partisipan untuk mempersonifikasi dirinya dengan karakter tokoh yang ada dalam ludruk. Oleh sebab itu, para pemain ludruk, terutama dalam cerita memberikan gambaran kehidupan sehari-hari, melalui tindakan sosial, motivasi, pilihan hidup, dan tujuan-tujuan hidup. Dalam hal ini, ludruk turut membawa penonton pada situasi dalam cerita serta emosi tokoh-tokohnya sehingga mampu mempengaruhi cara pandang penonton, terhadap setiap permasalahan yang mucul.

Supriyanto (2018:1) ludruk sebagai sebuah seni pertunjukan tidak hanya menjadi hiburan, namun ludruk memiliki arti dan peranan yang sangat mendalam bagi masyarakat Jawa Timur, baik dari segi sosial, emosional, dan kesejarahan. Sebab jika dilihat dari sejarahnya, ludruk telah menemani masyarakat dari masa ke masa, mulai dari periode Lerok Ngamen, Besut, dan Srudinan, Lerok pada masa kebangkitan nasional, pasca kemerdekaan RI, masa vakum pada tahun 1965-1968, masa orde baru 1968-1998, hingga periode pasca reformasi.

Di Jawa Timur utamanya daerah Surabaya banyak seniman-seniman ludruk yang terkenal baik sebelum era kemerdekaan maupun sesudah kemerdekaan. Salah satu nama seniman Ludruk yang paling dikenang oleh masyasakat Surabaya ialah Durasim, hingga namanya saat ini digunakan sebagai nama gedung pertunjukkan "Cak Durasim" di Taman Budaya Surabaya. Penggunaan nama tersebut tidak terlepas dari sejarah perkembangan ludruk di Kota Pahlawan. Sebab pada masa pendudukan Jepang Durasim banyak mengungkap penderitaan rakyat melalui kidung-kidung yang dibawakanya ketika bermain ludruk.

Saefurrohman (2013), menyatakan bahwa sebelum era kemerdekaan Durasim telah mendirikan grup ludruk yang diberi nama Ludruk Organisatie (LO). Ludruk tersebut sangat populer pada masa pendudukan Jepang, sebab kidunganya yang kerap kali menyidir pemerintah Jepang. Salah satu kidung yang melekat di hati masyarakat Surabaya sampai saat ini ialah "Pagupon omahe dara, melok Nipon tambah sengsara, (pegupon rumahnya burung dara, ikut Nipon/Jepang tambah sengsara”. Akibat dari 
kidung tersebut sewaktu pentas di Desa Mojorejo, Jombang Durasim ditangkap oleh Jepang dan dipenjarakan, hingga akhirnya Durasim wafat pada Agustus 1944.

Rofiq (2017) dalam petunjukkan ludruk, kidung Jawa Timur adalah fragmen dari pertunjukan tersebut. Dalam wujudnya kidung merupakan seni bertutur yang diiringi dengan gamelan, yang disampaikan oleh pelawak atau pemain ludruk. Kidung berisi pesan-pesan mengenai kehidupan yang meliputi masalah pendidikan, politik, kehidupan sehari-hari, dsb. yang dikemas dengan bahasa Jawa atau parikan dengan mngikuti gendhing Jawa Timuran.

Kidung Jawa Timur disampaikan dengan menggunakan bahasa Jawa varian ngoko, setiap bait kidung berisi nasihat tentang sikap, perilaku, budi pekerti dsb. Namun tidak jarang pesan dalam kidung mengandung sinisme, sebagai wujud kritik seniman ludruk dalam menyikapi permasalahan yang terjadi dalam kehidupan sehari-hari. Selain itu, dalam penyampaianya kidung diiringi gending Jula-Juli yang membuat lantunan kidung lebih estetis, sehingga penyampaian pesan dalam kidung lebih mudah untuk diterima oleh masyarakat.

Rismahaerani, dkk. (2017) kidung Jula Juli adalah parikan khas Jawa Timur. Sejenis pantun jenaka yang dikemas dengan Bahasa Jawa. Kesenian olah kata yang sudah ada sejak zaman dulu kala serta diwariskan secara turun-temurun. Fungsi parikan sebagai nasihat para orang tua kepada anak muda. Kidung Jula Juli saat ini menjadi bagian dalam pertunjukan ludruk. Kidung Jula Juli terdiri atas 2 atau 4 bait. Bait pertama atau kedua merupakan "umpan pembuka". Sedang bait ke 3 dan ke 4 adalah isi atau inti dari pesan yang ingin disampaikan. Rima akhir pada bait "pembuka" harus mirip atau sama dengan rima akhir pada bait isi, sehingga dengan demikian kidung Jula Juli terdengar lebih puitis.

Bedasar pada latar belakang tersebut dapat diketahui bahwa Kidung Jula Juli Jawa Timur yang menjadi bagian dari pertunjukan ludruk memiliki muatan sastra lisan. Sebab setiap larik dalam kidung tersebut tidak hanya indah untuk di dengarkan, tetapi juga mengandung pesan yang dapat dipahami dan diresapi. Oleh sebab itu, penelitian ini dilakukan untuk menggali lebih dalam fungsi yang terkandung dalam larik dan bait Kidung Jula Juli Jawa Timur. Untuk menggali fungsi pada kidung peneliti menggunakan teori fungsi Wiliam R. Bascom.

\section{Fungsi Sastra Lisan}

Menurut Wiliam R. Bascom (Sudikan, 2014: 151) terdapat empat fungsi folklor, yaitu: a) sebagai sebuah hiburan, b) sebagai alat pengesahan pranata-pranata dan lembagalembaga kebudayaan, c) sebagai alat pendidikan anak-anak, d) sebagai alat pemaksa dan pengawas agar norma-norma di dalam masyarakat dapat berlaku. Apabila dikaitkan dengan objek penelitian, yakni Kidung Jula-Juli Jawa Timur, dapat diuraikan sebagai berikut. a) Kidung Jula-Juli dalam pertunjukan Ludruk merupakan satu struktur seni pertunjukan yang sangat khas, identik bagi masyasakrat Jawa Timur, bahwa di dalam kesatuan pertunjukan tersebut penonton dapat memperoleh hiburan yang memiliki muatan sastra lisan, b) melalui Kidung Jula-Juli baik secara langsung maupun tidak 
langsung masyarakat diingatkan kembali akan pranata-pranata yang berlaku di masyarkat, c) lirik kidung Jula-Juli yang diakhiri dengan kesamaan bunyi/rima akhir tidak saja dapat dinikmati oleh orang dewasa, namun juga dapat dinikmati oleh orang dewasa, bahkan anak-anak, d) melalui sastra lisan seperti kidung Jula-Juli, normanorma yang ada tetap berlaku di masyarakat.

\section{B. METODE PENELITIAN}

Peneliti menggunakan metode kualitatif. Pemilihan metode penelitian disesuaikan dengan tujuan penelitian. Adapun sumber data yang digunakan dalam penelitian ini ialah enam video pertunjukan ludruk, dengan judul sebagai berikut; Soto Gagak, Kidung Lawakan, Kemanten Kisinan, Tumpeng Maut, Kejeglek Anak Dewe, Balai Kota. Semua data tersebut diperoleh dari youtube. Semua Kidung Jula Juli yang digunakan sebagai sumber data tersebut dibawakan oleh Cak Kartolo (CK). Sedangkan data dalam penelitian ini ialah tuturan yang dialihwanahakan dalam bentuk bait dan larik yang mengandung fungsi-fungsi tersebut di atas.

Dalam memperoleh data, peneliti menggunakan teknik pengumpulan data melalui beberapa tahapan sebagaimana berikut; 1) mencari video pertunjukan ludruk/kidung jula-juli yang dibawakan oleh Kartolo di youtube, 2) mengunduh video pertunjukan ludruk yang sudah diidentifikasi sebelumnya, 3) menyimpan video pertunjukan ludruk tersebut dalam satu folder, 4) memberi identitas pada setiap video (contoh; Kidung 1, 2, dst.).

Selanjutnya, untuk mencapai tujuan penelitian peneliti menggunakan teknik analisis data dengan beberapa tahapan sebagai berikut; 1) transkripsi Kidung Jula Juli pada enam video tersebut, 2) pengodean pada setiap data yang sesuai dengan tujuan penelitian, untuk memudahkan peneliti dalam melakukan identitikasi, 3) klasifikasi data berdasarkan empat fungsi Kidung Jula Juli, 4) interpretasi data berdasarkan empat fungsi tersebut pada setiap bait Kidung Jula Juli. Pada kegiatan ini digunakan prinsip kerja yang dikemukakan oleh Ricour (Poespoprojo, 2004:112-113) Interpretasi dalam hermeneutika dirumuskan sebagai teori operasi-operasi pemahaman dalam kaitanya dengan interpretasi kebudayaan sebagai teks, interpretasi sebagai perbedaan suatu arti yang tersembunyi di dalam arti yang tampak. Artinya, interpretasi digunakan untuk menguraikan arti atau makna yang tersembunyi dalam kebudayaan sebagai teks (objek) penelitian, (5) yang terakhir ialah pengambilan kesimpulan yang berdasar pada keseluruhan analisis data.

\section{PEMBAHASAN}

Pada bagian ini akan dibahas hasil penelitian yang dilakukan terkait fungsi Kidung Jula Juli Jawa Timur. Pada pembahasan yang akan dilakukan perlu dijelaskan terlebih dahulu terkait dengan kode-kode yang digunakan peneliti dalam memberi identitas setiap data yang digunakan. Adapun kode-kode yang digunakan ialah sebagai berikut; K (kidung Jula-juli), 1 (nomor data/kidung), B (nomor bait), dan 1 (nomor bait). Pengodean tersebut dilakukan untuk memudahkan peneliti dalam memberikan identitas setiap data. Selanjutnya pada bagian ini akan dibahas empat fungsi Kidung Jula-Juli dalam pertunjukan ludruk yang didasarkan pada teori fungsi Wiliam R. Bascom. 


\section{a. Sebagai Sebuah Hiburan}

\section{K.2.B.7}

Thenguk-thenguk aku nemu gethuk

Ana cewek kok celuk-celuk

Bareng idek aku ditapok

Kenal se..pi..san kok wes medhotno sabuk.

\section{K.1.B.1}

Moro-moro ngajak kawinan

Aku dorong nduwe penggawean

Kemanten anyar gelek gegeran

Klambi situk mlebu rombengan..

Apabila berbicara masalah sastra lisan sebagai hiburan terdapat dua hal yang melekat pada sastra lisan kidung Jula Juli, yakni; pertama ialah keunikan/keistimewaan dibanding dengan sastra lisan yang lain, 2) aspek estetis pada setiap penggunaan rima akhir pada kidung Jula Juli. Hardjoprawiro (Rofiq, 2017)“Terdapat keistimewaan dan keunikan dalam kidungan Jawa Timuran, baik dari segi bentuk maupun cara melagukannya, yang berbeda dengan jenis nyanyian rakyat yang lain. Selain itu, eksistensi kidung Jula Juli yang menjadi bagian dalam transformasi pertunjukan ludruk, menunjukkan bahwa kesenian tersebut merupakan sebuah hiburan yang diterima dengan baik masyarakat.

Selanjutnya, aspek keindahan dalam kidung Jula Juli juga tampak pada data tersebut, bahwa setiap rima akhir pada larik terdapat kesamaan bunyi. Hal itu merupakan wujud adanya kesamaan antara kidung Jula Juli dengan pantun. Rismahaerani, dkk. (2017) Parikan/Kidung Jula Juli secara sturktur umumnya terdiri atas 2 atau 4 bait. Bait ke-1 atau ke-2 merupakan "pembuka". Sedang bait ke-3 dan ke-4 berisi pesan yang hendak disampaikan. Rima akhir pada bait ke-1 dan ke-2 harus mirip dengan bait ke-3 dan ke-4 sehingga jatuhnya terdengar enak ketika dilantunkan.

\section{b. Sebagai Alat Pengesahan Pranata-pranata yang ada di masyarakat}

\section{K.5.B.2}

Wang urip ngunu dulur

Diwajibno berusaha

Kanggo nyukupi kebutuhan ke...lu...ar...ga.. hoohoho eoh haehea

Aja sampek, menghalalkan segala cara

Golek rezeki sing ridhlo, lan sing.. ba...ro..kah...

Mula kudu ngerti nang kewajiban

Aja sampek, nindakno penye..le...we...ngan..

Wang urip ngunu nduwenono semboyan

Nglakoni jujur temen cek lancar tolek san...dang.. pa...ngan... 
Kutipan tersebut secara garis besar berisi tentang pesan yang disampaikan kepada masyarakat, mengenai kewajiban seorang kepala keluarga dalam mencukupi kebutuhan keluarganya, bahwa dalam upaya mencukupi kebutuhan seseorang perlu memegang prinsip-prinsip kejujuran, kesabaran, dan keberterimaan, artinya segala upaya yang dilakukan harus didasarkan pada norma-norma yang berlaku. Sehingga, rezeki yang diperoleh merupakan rezeki kemanfaatan bagi pribadi serta keluarganya.

Rofiq, (2017) menyatakan bahwa dalam kidungan Jawa Timuran terdapat pesan-pesan budaya yang berkaitan dengan sistem kepercayaan, sistem norma dan nilai-nilai kehidupan yang dapat menjadi renungan bagi masyarakat. Lebih lanjut Rismahaerani, dkk (2017) Kidung Jula Juli merupakan gaya nembang khas Jawa Timur yang unik, jenaka, menggelitik, terkadang penuh dengan sindiran halus sampai terang-terangan /sarkasme, bahkan tidak jarang lirik dalam kidung berupa kritik yang membangun, memotivasi. Selain itu, kidung Jula Juli berisi ejekan yang tidak membuat pendengarnya merasa marah, tetapi merasa tergelitik, sebab mereka menyadari betapa mengenanya kritikan tersebut.

\section{c. Sebagai Alat Pendidikan Anak- Anak}

\section{K.3.B.8}

Nomer enem dulur penting ngenek'i pendidikan

Mula iku ngunu, io kanggo kema...juan

Lek kabeh pinter, lan kabeh pengala..man

Isa mencapai, io nang kemakmuran..

Aku dewe yu saiki io getun mburi

Sekolah gak nutuk kancane kok kesusu ra...bi

Anak akeh cak nyambut gaweku gak mesti

Bareng ditarik blonjo dadak brengosku mbrondo..li

Kutipan tersebut secara eksplisit merupakan wujud dari keresahan CK dalam melihat realitas kehidupan masyarakat saat ini, yang dapat digunakan sebagai referensi tentang pentingnya pendidikan, terutama pendidikan formal. Sebab dalam pandangan masyarakat modern, pendidikan formal sudah menjadi suatu sarana yang harus ditempuh oleh anak-anak, mulai dari tingkat dasar, menengah, hingga atas, sebagai salah proses menjadikan manusia seutuhnya. Dengan demikian terjadi proses-proses transfer knowledge, yang dapat digunakan sebagai bekal dalam mencapai tujuan hidup.

Selain itu, dalam kutipan tersebut CK juga menyampaikan pesan kepada setiap anak, untuk menjaga diri ketika mereka masih menginjak bangku sekolah. Agar tidak terpengaruh budaya-budaya negatif, yang masuk melalui pergaulan bebas, serta interaksi baik secara langsung maupun melalui media sosial. 


\section{K.6.B.6}

Cak sodikin wang bebojoan aja didadekno sedina rong dina

Mula usahakno isa dadi sampek tu..wa..

Ayo sing rukun kaya mimi lan mintuna

Supaya diconto mbarek anak putu ki..ta..

\section{K.6.B. 7}

Sing marahi gegeran ayo dihindari

Pari basan piring elok benthet iku wes me..sti..

Lek salah sijine isa menghindari..

Isa dadi kaki-kaki.. lan nini-nini..

\section{K.6.B.8}

Dadi wang tuwa Bu peno kudu sing eling

Minterna anak iku paling pen..ting..

Engko diencepi cewek ae pikirane wes pusing

Ndok omah lenger-lenger poleh kaya kucing ger..ring

Kutipan tersebut berisi tentang pesan kepada masyarakat, terutama bagi kaum muda, tentang pentingnya dalam menjaga keharmonisan keluarga. Sebab keharmonisan sebuah keluarga menjadi suatu ukuran tingkat kedewasaan, kesiapan, serta kematangan setiap pasangan dalam menjalani kehidupan yang baru. Sehingga sangat diharapkan dalam sebuah keluarga mengerti dan memahami kewajiban masing-masing.

Selain itu, pada kutipan di atas juga disampaikan bahwa pentingnya memberikan pendidikan terhadap seorang anak. Hal ini dapat diwujudkan dalam pembelajaran yang bersifat formal maupun non-formal. Sebab dalam proses pendidikan seorang anak dapat mengembangkan potensinya untuk memiliki kekuatan spiritual keagamaan, pengendalian diri, kepribadian, kecerdasan, akhlak, serta keterampilan yang sesuai dengan potensi masing-masing individu. Dengan demikian proses-proses yang terjadi dalam pembelajaran di sekolah menjadikan manusia seutuhnya.

\section{d. Sebagai Alat Pemaksa Dan Pengawas Agar Norma-Norma Di Dalam Masyarakat Dapat Berlaku}

\section{K.6.B.4}

Mulane sing penting saling menyintai

Sak pada-padane saling meng..hor...ma...ti...

Meningkatkan sikap tenggang rasa

Aja sampek lali nilai-nilai kemanusiaan

Ayo dijun..jung ting...gi...

\section{K.6.B.5}

Nek ana persoalan aja kesusu emosi

Didolekki solusine lewat nego..i...sa...si...

Mula adu fisik ayo dihindari 
Segala persoalan diselesaikno seca...ra.. da...mai...

Kutipan tersebut, berisi tentang pentingnya sikap saling menghormati dalam menyikapi berbagai permasalahan hidup. Sebab dengan toleransi, keharmonisan dan keselarasan dalam kehidupan masyarakat akan tercipta dengan baik, dengan demikian setiap permasalahan yang dihadapi tidak akan menimbulkan konflik baik antar individu maupun antar kelompok. Hal ini diperkuat oleh pernyataan Rismahaerani, dkk (2017) Kidungan merupakan salah satu sarana yang cukup ampuh untuk memperbaiki kondisi ataupun gaya hidup, kebiasaan/pola golongan tertentu dalam masyarakat khususnya Jawa Timur, yang dianggap kurang pas atau bahkan tidak pasa dengan kebiasaan warga setempat, baik menyangkut masalah toleransi, sopan santun, saling mernghormati, dsb.

Selanjutnya, pesan dalam kutipan tersebut apabila dikaitkan dengan peramasalahan dalam konteks komunikasi saat ini, yang cenderung bebas terutama dalam menggunakan media sosial, masyarakat harus berpegang teguh terhadap sikapsikap tersebut di atas guna menumbuhkan serta menjaga sikap tenggang rasa dalam berpendapat, sehingga dengan demikian norma-norma yang berlaku di masayarakat akan tetap menjadi pedoman dalam menciptakan kehidupan yang rukun, selaras, serta harmonis.

Berdasarkan hasil dan pembahasan tersebut, dapat diketahui bahwa kidung Jula Juli sebagai bagaian dari pertunjukan ludruk memiliki beberapa fungsi sebagaimana tersebut di atas, fungsi-fungsi tersebut merupakan wujud bahwa kesenian rakyat memiliki peranan sebagai kontrol sosial dalam kehidupan masyarakat, sehingga normanorma dapat berlaku di masyarakat.

\section{KESIMPULAN}

Berdasarkan beberapa telaah tersebut, dapat diketahui bahwa kidung Jula Juli dalam Ludruk Jawa Timur memiliki beberapa fungsi, di antaranya; sebagai hiduran, sebagai pengesahan pranata sosial, sebagai media pendidikan bagi semua lapisan masyarakat, serta sebagai alat pemaksa dan pengawas norma-norma yang berlaku di masyarakat.

Berdasarkan hasil dan pembahasan tersebut kidung Jula Juli berisi tentang nasihat-nasihat yang semuanya bersumber dari kehidupan masyarakat. Pesan-pesan tersebut tentunya dapat digunakan oleh masyarakat sebagai refleksi dalam menyikapi permasalahan kehidupan.

Di dalam penelitian ini tentunya diperlukan proses atau tahapan penyempurnaan hasil penelitian. Oleh sebab itu, peneliti sangat memerlukan saran dari pembaca untuk memberikan koreksi terhadap apa yang tersaji dalam penelitian ini. 


\section{DAFTAR PUSTAKA}

Bandem, I Made dan Sal Murgiyanto. 2000. Teater Daerah Indonesia. Yogyakarta: Kanisius.

Poespoprodjo, W. 2004. Hermeneutika. Bandung: CV Pustaka Setia.

Prasisko, Yongki Gigih. 2018. Ludruk Jember: Ritual Masyarakat Peranatuan. Jurnal Parafrase Vol. 18 No. 1. http://jurnal.untagsby.ac.id/index.php/parafrase/article/view/1384. Diakses pada 10 Desember 2019

Rismahareni, Ayu, dkk. 2017. Kajian Interaksionisme Simbolik Kidung Jula-Juli Ludruk pada Pementasan Ludruk Irama Budaya Surabaya. Jurnal Fenomena. 4.2:78. http://ejournal.unitomo.ac.id/index.php/pbs. Diakses pada 9 September 2019 .

Rofiq, Ainnur. 2017. Kidung Jawa Timuran dalam Pertunjukan Ludruk Budhi Wijaya Jombang. Jurnal Antro Vol. VI No. 1. http://journal.unair.ac.id/downloadfullpapers-aun285b4e76622full.pdf. Diakses pada 10 Desember 2019.

Saefurrohman, Nandi. 2013. Sidik Wibisono Pelestari Kidungan Jawatimuran. Jurnal Pengkajian dan Penciptaan Seni, Vol. 4, No. 6. https://e-journal.stkwsurabaya.ac.id/index.php/itr/article/view/29. Diakses pada 10 Desember 2019.

Sudikan, Setya Yuwana. 2014. Metode Penelitian Sastra Lisan. Lamongan: CV. Pustaka Ilalang Group.

Supriyanto, Henricus. 2018. Ludruk Jawa Timur dalam Pusaran Zaman. Malang: Intrans Publising.

Sudikan, Setya Yuwana. 2014. Metode Penelitian Sastra Lisan. Lamongan: CV. Pustaka Ilalang Group.

Sugiri, Eddy, Satya DTK, dan Purwantini (2003). Fungsi, Bentuk, dan Makna Kidungan Seni Ludruk Pada Era: Suatu Kajian Etnolinguistik. Universitas Airlangga, Surabaya.

Supriyanto, Henricus. 2018. Ludruk Jawa Timur dalam Pusaran Zaman. Malang: Intrans Publising. 